has long been a subject for discussion"; by whom one wonders?

But the more serious problems of the book begin with its title. It is basically the story of nuclear fission, as its subtitle indicates, yet the title clearly refers to nuclear fusion - a reference reinforced by the exploding hydrogen bomb on the jacket cover. Careful reading of the text makes clear the distinction between fission and fusion, but hasty readers may be left confused.

More important is the question of the distribution of emphasis inherent in the structure of the book. Surely, the critical element in our current nuclear predicament is the combination of the fusion or hydrogen bomb, with its capacity for unlimited growth in explosive power, and a missile technology capable of accurately placing such bombs on target within minutes of launching. But no sense of the crucial nature of this development emerges from the brief concluding section of the book. Indeed, what is the moral of Clark's story? He says all the "right" things about the perils of nuclear weapons, and dangers of nuclear radiation - except for one sentence in his concluding paragraph, which plays into the hands of those currently trying to prepare the public for "limited"' nuclear wars. He says,

It would be tragic if a limited nuclear exchange, halted after each side had experienced the agony of one city put to the bomb, were necessary to bring men to their senses and to realize, at last, that there are no victors in nuclear war.

Not only would it be tragic (reminding one of the man being led to his execution who assures the audience that this will certainly teach him a lesson!); it is so unrealistic a prospect, as Lord Mountbatten came to realize, that its contemplation as a pedagogical device seems irresponsible.

Finally, there is the broader question raised by the context in which Clark's account places the story of nuclear weapons. Focusing attention in the opening sections exclusively on the development of nuclear physics fosters the all too prevalent view of science and technology as independently evolving structures. For more direct evidence of this outlook, one need look no further than the opening sentence of Lord Zuckerman's preface:

The keystones of our century's history are those scientific and technological advances - radio, the internal combustion engine, antibiotics which have determined the pattern of life which half the world now leads, and for which the other half strives . . .;

or the opening paragraphs of Clark's first chapter. After evoking the political and social turmoil of late 1919 , inflation and starvation in Central Europe, civil war in Russia, soldier's soviets in Britain, American rejection of the League, Clark continues:

Yet this record of battery and barricade, which added a bloody touch to the first autumn of peace, was of infinitely less importance to the future of the human race than three events in the worlds of astronomy and physics.

More disturbing than Clark's particular choice of three events (about which more could be said) is the very idea of singling out some group of scientific and technological developments and setting them in apposition to the symptoms of vast social, economic and political upheavals in evaluating their "importance to the future of the human race"'. I think the evidence exists, in Clark's book and elsewhere, to sustain Raymond Williams' recent judgement:

In the case of nuclear weapons, nothing is more evident than that they were consciously sought and developed, and have continued to be consciously sought and developed. It is true that, as so often in modern technological innovations, much of the basic research had been done for quite other reasons, without foreseeing this particular result. But again as in many other comparable cases, the crucial moment of passage from scientific knowledge to technical invention, and then from technical invention to a systematic technology, depended on conscious selection and investment by an existing social order, for known and foreseen purposes (New Left Review 124, Nov-Dec. 1980, p.365)

Until we grasp this element of intention in the process of research and development in modern technology, as Williams puts it elsewhere, I fear that efforts to organize movements to control the uses of that technology will be hampered by the feeling that such developments really are inevitable. And in the case of nuclear weapons, I am not certain how much time we have left to learn the lesson.

John Stachel is Professor of Physics at Boston University, currently editing the Einstein papers at the Institute for Advanced Study, Princeton.

\section{More pie in the sky}

\section{Paul Davies}

Gravity, Black Holes, and the Universe. By Iain Nicolson. Pp.264. ISBN 0-7153-7849-X/0-470-027111-6. (David \& Charles/Halsted: 1981.) $£ 10.95, \$ 24.95$.

BOoKs on black holes and the Universe range from postdoctoral research treatises to the wildest distortions of science fiction and the occult. Since the explosion of interest in astronomy in general and black holes in particular, which began during the $1960 \mathrm{~s}$, the market has been flooded with literature on matters cosmic. How can the discerning reader tell where to go for both reliable and entertaining treatment?

Having spent many years myself on cosmological and astrophysical research, I do not envy the task of the professional writer who has to attempt to master the technical literature of a difficult and developing subject, and distil out the features that the scientific community considers to be well established. Still more demanding is the task of grading the various conjectural topics, some of which can be bizarre, into degrees of seriousness.

Take one example: travel through a black hole. Certain solutions of Einstein's field equations display the weird property that they can be continued into regions of space and time that are forever inaccessible to us unless we fall into a black hole. These "other" spacetimes (infinite in number) are sometimes called other universes. Do they exist?

In the sense that certain idealized model spacetimes admit other universes, then the subject is a serious one, and schematic representations of these universes appear in textbooks and mathematical monographs. In spite of this, the models concerned are not supposed to apply to the real world, because they involve certain simplifications (for example, the absence of matter) that manifestly fail in reality. The prevailing opinion is that a more realistic model would not display these other universes, and that an observer who falls into a black hole will not, after all, emerge in a hitherto unknown spacetime, but will crash to oblivion in a region of unlimited tidal stress.

A writer may cover his subject thoroughly yet still miss such subtleties and proclaim that modern physics definitely predicts the existence of other universes. Certainly a glance at a textbook could give that impression. Iain Nicolson is to be congratulated that on this, and many other contentious and delicate issues, he has not only got the facts right, but has conveyed the correct degree of scepticism or reliability appropriate to each conjectural topic.

There is much more to this book than black holes, however. The author takes us gently through Kepler's laws, newtonian mechanics and special relativity, before getting on to the equivalence principle, curved spacetime and the general theory of relativity. $\mathrm{He}$ also applies his thoughts to the expanding Universe, and the intriguing topic of its ultimate fate.

The book is nicely illustrated with line drawings and photographs, and has a short bibliography. Although certain advanced topics, such as quantum aspects of black holes, are courageously included (and skilfully handled), the book should still appeal to general readers having only a nodding acquaintance with physics and astronomy.

My initial reaction to this book was to wonder where yet another treatment of this trendy subject could possibly fit in to an already crowded market. The answer is that it is one of the few books that maintains a reliable scientific perspective and a careful treatment, yet covers most of the "fun" topics in detail.

Paul Davies is Professor of Theoretical Physics at the University of Newcastle upon Tyne. 